This is an Accepted Manuscript of an article published by Taylor \& Francis in Disability and Rehabilitation on 3 July 2016, available

online: http://www.tandfonline.com/10.1080/09638288.2016.1198428

1 June 2016

\title{
Cooperation of return-to-work professionals: the challenges of multi- actor work disability management
}

Jyri Liukko

Finnish Centre for Pensions

Research Department

00065 Eläketurvakeskus

Finland

\author{
Niina Kuuva \\ University of Helsinki \\ Ruralia Institute \\ Lönnrotinkatu 7 \\ 50100 Mikkeli \\ Finland
}

Corresponding author:

Jyri Liukko, Finnish Centre for Pensions, FI-00065 Eläketurvakeskus, Finland

Tel: +358294112154 or +358 505988 665, Fax: + 35829411 2410, e-mail: jyri.liukko@etk.fi 


\section{Abstract}

Purpose

This article explores which concrete factors hinder or facilitate the cooperation of return-to-work (RTW) professionals in a complex system of multiple stakeholders.

Method

The empirical material consists of in-depth interviews with 24 RTW professionals from various organizations involved in work disability management in Finland. The interviews were analysed using thematic content analysis.

Results

The study revealed several kinds of challenges in the cooperation of the professionals. These were related to two partly interrelated themes: communication and distribution of responsibility. The most difficult problems were connected to the cooperation between public employment offices and other stakeholders. However, the study distinguished notable regional differences depending primarily on the scale of the local network. The main areas of improvement proposed by the interviewees were related to better networking of case managers and expansion of expertise.

\section{Conclusions}

The article argues for the importance of systematic networking and stresses the role of public employment services in the multi-actor management of work disabilities. The article contributes to existing work disability case management models by suggesting the employment administration system as an important component in addition to health care, workplace and insurance systems. The study also highlights the need for expansion of expertise in the field.

\section{Keywords}

Return to work, cooperation, work disability, unemployment, vocational rehabilitation 


\section{Introduction}

The significance of cooperation and interaction between different stakeholders has been stressed in several recent studies as one of the most important features of the successful return-to-work (RTW) of persons with work disabilities $[1,2,3,4,5,6,7,8]$. An essential reason behind the increasing emphasis on cooperation lies in the expanded conceptualization of work ability. It is nowadays widely recognized that work (dis)ability is not only a medical or individual issue but thoroughly a societal and organizational phenomenon as well $[9,10]$. Accordingly, rehabilitation and RTW interventions often require various actors in addition to clinical health care.

Many of the recent studies on work disability management have been focused either on specific disease groups or certain subsystems like health care or the workplace $[5,11,12,13,14]$. Instead research on the functioning of the whole network of institutions managing work disabilities, including all possible stakeholders, is still scarce, even though the need for such multipartite research has already been recognized long ago.

The purpose of this article is to examine which concrete factors hinder or facilitate the cooperation of the most important actors dealing with work disability and RTW issues in Finland. The study is based on in-depth interviews with RTW professionals in various organizations. The Finnish system presents a good case for studying this question as there are numerous different actors - operating in both public and private sectors - involved with the prevention and management of work disability. These include occupational health care, primary and special health care, employers, (social) insurers, rehabilitation providers and public employment services, which all have their individual roles.

According to several expert working groups and previous research literature, the main problems in work disability management and the rehabilitation system in Finland are related to the fact that the 
system is very complex and fragmented $[15,16]$. The key concern, already for decades, has been insufficient cooperation between different authorities. The complexity of the system makes it difficult both for clients and professionals to find the best paths to the right services. The Organisation for Economic Co-Operation and Development (OECD)[17] has criticized in particular the vocational rehabilitation system in Finland and suggested that the responsibilities of the authorities should be clarified and rehabilitation financing reformed in order to decrease the rehabilitees' transition between different authorities. Also among local experts the general view seems to be that the cooperation between the stakeholders is not optimal. Of the greatest concern is the fact that nobody has an overall responsibility for a client's situation.

The Finnish case is not unique. Many other European countries face similar challenges related to the complexity of work disability management and rehabilitation systems [18, 19, 20]. For example, recent Swedish studies on the interaction of work disability professionals have shown that the collaboration with other stakeholders is often rare and occurs usually late in the sick leave process $[5,7]$.

During recent years however, there have been several legislative reforms in Finland aiming to improve the cooperation of employers, occupational health care, public health care and insurers in work disability prevention. These reforms have been influenced by the increasing evidence of greater effectiveness of workplace-based interventions as opposed to interventions provided outside the workplace $[2,11,21,22,23]$. The new direction is promising. An increasing number of employees are benefitting from vocational rehabilitation and since 2008 also the number of new disability pensions has decreased significantly.

Most of the reforms have concentrated on preventing work disability and promoting the early return to work of those people who have a job (and who usually work on a permanent contract). This tendency seems reasonable as such. However, the flip side of the emphasis on employees is the fact 
that there is also a fair amount of unemployment among people with work disabilities $[24,25,26$, 27]. As the recent reforms have not improved the situation of unemployed persons, the biggest challenges now seem to be related to the cooperation of the actors working with unemployed people with work disabilities. These are especially public employment offices, public health care, the Social Insurance Institution (Kela) ${ }^{1}$ and also employee pension institutions (which manage statutory earnings-related pensions) in cases where an unemployed person still has the right - due to recent working history - to vocational rehabilitation covered by an employee pension institution.

The present article addresses this peculiar arrangement by exploring specific problems in the management of work disability. Although we take all the stakeholders into account, the focus is, for the reasons mentioned above, especially on issues related to simultaneous unemployment and work disability. The main question is: what kind of problems do return-to-work professionals face in their cooperation with each other? These problems are closely related to a certain kind uncertainty that seems to be an inherent feature of RTW interventions. They are uncertain in the sense that each case is unique, requiring a special kind of experiential, local and case-specific know-how whereupon it might be difficult to systematically lean on evidence-based (statistical) knowledge about probable outcomes of different actions $[28,29]$. In addition, the complexity created by the multi-actor nature of work disability management further increases the uncertainty of the system.

As Pransky et al. [10] and Loisel et al. [30] highlight, the primary difficulty at a societal level is an inability to coherently implement evidence-based RTW solutions by different stakeholders. In this article we argue that this is related to the inherent uncertainty present in the multi-actor RTW strategies: the larger the number of separate organizations around a person, the more possibilities there are for increasing uncertainty. We focus on two partly overlapping themes that were the main sources of uncertainty in the cooperation of RTW professionals. These are, firstly, communication,

\footnotetext{
${ }^{1}$ Kela manages a big part of social security in Finland, for example family benefits, health insurance, rehabilitation for certain groups, basic unemployment security, housing benefits, financial aid for students and basic pensions.
} 
and secondly, distribution of responsibility between the actors. Moreover, we present the main ideas advanced by the interviewees for improving the cooperation. At the end of the article, we discuss the possibilities of systematic interorganizational networking and expansion of expertise as the main tools for enhancing communication and distribution of responsibility and thus reducing uncertainty in RTW interventions.

\section{Interorganizational Management of Work Disability}

An influential and practical model for studying work disability that gives attention to the multiplicity of actors and systems around the worker with disability was introduced by Loisel et al. $[9,30]$ in the beginning of the millennium. The model has several names: the disability prevention management model, the arena in work disability prevention or the case-management ecological model [31]. This model recognizes the significance of four subsystems that influence the worker's situation: the workplace system, health care system, compensation/insurance system and personal system.

Our study draws on this model but revises it by focusing on the three professional systems of the model - the workplace, health care and insurance systems - and by adding one important actor which may be regarded as part of the insurance system but which, at least in the Finnish context, actually forms an independent system, the employment administration system. In this system the main stakeholder in Finland is public employment services organized primarily by regional public employment offices. The main reason that public employment services cannot be included in the insurance system is that they are not responsible for unemployment (insurance) benefits but merely for employment services. Moreover, after a major reform in 2013, public employment offices have in a way receded further from the insurance system in that they are no longer responsible for 
vocational rehabilitation of unemployed persons but only direct their clients with work disabilities to rehabilitation organized by insurance institutions.

\section{Method}

The research material consists of semi-structured theme interviews with 24 work disability and RTW professionals. The length of the interviews varied between 90-120 minutes. The interviewees were chosen so that there were at least one to two professionals involved with work disability management from each relevant organization (see Table 1). Five of the interviewees worked at rehabilitation providers, four at employee pension insurers, four at the Social Insurance Institution Kela (of which some also worked part-time at labour force service centres ${ }^{2}$ ), three at public employment offices, three in special health care, two in occupational health care, two in personnel administration at workplaces and one at a labour force service centre. The interviews were conducted individually, apart from one interview, in which two persons from the same organization were interviewed at the same time. In order to examine regional differences, half of the interviewees were from the capital region (1) and half from the Southern Savonia region (2) in eastern Finland. The interviews were conducted in May and June 2014. The interviewees were different kinds of RTW professionals, such as vocational rehabilitation experts or other kinds of work disability case managers (see Table 1). The educational background of the professionals was mainly in social sciences, social work, psychology, nursing or corresponding fields.

\footnotetext{
${ }^{2}$ Labour force service centres are targeted for a relatively small group of long-term unemployed who need individual support and special social services. The centres are organized together with municipalities, public employment offices and Kela. The majority of the unemployed persons are clients in public employment offices.
} 
All the interviews were recorded and transcribed word for word. The content of the interviews was analysed thematically focusing on the most salient themes related to the problematics of cooperation on the one hand, and the propositions for improving the cooperation on the other. All of the interviews included four general themes: 1) the content of the interviewee's own work and the tasks of their own organization in work disability management, 2) cooperation between the actors, 3) customer orientation and case-specific discretion and 4) the influence of recent reforms on the cooperation. In this article the focus is particularly on the first two themes. The content of the material was first classified into subcategories partly inductively and partly according to the four themes of the interviews. After that the content was categorized into broader themes including communication, distribution of responsibility and proposed improvement ideas.

\section{Results}

The interviews revealed two main themes that form the primary sources of uncertainty in the cooperation of RTW professionals in Finland. These were problems in the communication and in the distribution of responsibility between different organizations. In the following sections, we illustrate these two themes with examples referred to by the interviewees. After that we depict the most important areas of improvement suggested by the interviewees.

\section{Communication}

The most significant problems in the cooperation of the professionals were related to the communication between professionals in different organizations. The problems of communication seem to arise mainly from organizational rigidity, and the variation between organizations is wide. According to the interviewees from insurers and rehabilitation providers, communication works 
relatively well within the insurance system which in Finland consists of employee pension and other insurers, the Social Insurance Institution (Kela) and rehabilitation providers which work for the insurers. An important factor in their communication is an established network of insurers (excluding Kela) and rehabilitation providers that includes an extensive information technology (IT) system praised by many of its users among the interviewees.

However, the insurance system and health care institutions do not have any common IT systems for communication and exchange of documents. Also communication within the health care system, especially between special health care, primary health care and occupational health care was regarded as far from flawless, largely due to inadequate joint IT systems. For example, in many cases occupational health care may not be aware of all the information and diagnoses made elsewhere. In these situations some relevant information might be missing, for example when an occupational physician evaluates an employee's work ability or directs him or her to apply for vocational rehabilitation from a pension insurer. In general, the lack of comprehensive joint IT systems was regarded as one of the main reasons for the problems in communication.

\section{The biggest Problems were related to simultaneous Unemployment and Work Disability}

On the basis of the interviews, the biggest problems in communication seem to be related to the interaction of the employment administration system with the health care and insurance systems. Thus a group that loses out in the whole work disability management scheme in Finland is clearly unemployed persons with work disabilities who are not entitled to occupational health care. Since 2012, public employment offices have been required to direct unemployed persons with disabilities to medical examinations in primary health care. However, the communication between public employment offices and primary health care as regards the results of these examinations seems to be insufficient. The interaction on the whole between health care and public employment offices 
was described as "scattered" and "excruciatingly slow" (H11, rehabilitation expert, public employment office). Also the communication between primary health care and occupational health care was considered inadequate particularly in situations when an employee loses his or her job and thus also access to occupational health care.

There appear to be substantial differences in how easy it is to contact the right professional in another organization or to get direct personal contact details. In the case of public employment offices, several interviewees - in particular from pension insurers and rehabilitation providers described their frustration as they had been compelled to call the general customer service number and wait on the line together with the clients (at the time of the interviews public employment offices did not yet have a general phone number for authorities, but in the beginning of 2015 such a number was established).

Contacting employment administration in particular is sometimes incredibly difficult (...) some employment offices have almost driven me crazy. (H1, work ability coach, occupational health care)

All in all, most of the interviewees collaborating with employment administration considered the interaction between public employment offices and other organizations to be exceptionally inadequate. In addition to the ways of communication described above, an often mentioned problem, also in this case, was the lack of any common IT system between employment administration and other organizations. According to several interviewees, there is however, a great need for improving the situation as many people with disabilities have shorter or longer terms of unemployment during their RTW process. 
The narratives of the interviewees were fairly similar in many issues. There was nevertheless one big difference which appeared between small towns and the capital region. Unlike their colleagues in the Helsinki metropolitan area, several professionals in smaller towns reported that despite the organizational rigidity, the communication can often be quite smooth, also with public employment offices. The reason they gave was close and functioning personal relationships. They know each other personally and they also know who to call in other organizations in each case. In other words, they have found informal ways to overcome the organizational borders and restrictions. Only contacting primary health care was reported as being difficult, precisely because there is not necessarily any particular person to contact in work disability issues. Unlike in special health care in hospitals, in some municipalities there are no social workers in primary health care, which was considered a problem.

Also in primary health care, it would be very necessary for there to always be a social worker to act as a contact person in all kinds of matters. (H2, rehabilitation manager, rehabilitation provider)

Several interviewees stressed that social workers in health care are crucial for good communication between organizations. They seem to facilitate particularly the communication between special health care and other organizations, including public employment offices.

\section{Distribution of Responsibility and the changing Role of Employment Administration}

The greatest concern in the interviews seems to be that nobody has a clear comprehensive responsibility for the clients in the management of work disability in Finland. This element stands out in situations where there are several stakeholders (and systems) around the same client 
simultaneously. On the basis of the interviews these kinds of situations include a lot of uncertainty as regards the distribution of responsibility. Similarly as in the examples related to communication, this seems to be the case especially in those, not so unusual, situations where the same person simultaneously faces working capacity problems and unemployment. Those who have stable jobs are in a good position, but if employment and thus the follow-up of occupational health care ends, the situations becomes more difficult. In the following, we focus particularly on the changing role of the employment administration system as regards the distribution of responsibility in RTW interventions.

Especially the interviewees from pension insurers and rehabilitation providers reported that the distribution of responsibility is most unclear in cases where people would benefit both from vocational rehabilitation covered by their pension insurer and public employment services, such as specific training or careers counselling for the unemployed. Now unemployed people with disabilities seem to be rejected from the public employment services they may need in consequence of having a right to and especially of having a preliminary award for vocational rehabilitation covered by their pension insurer, even if the rehabilitation measures will not be organized until after several months. The preliminary award for vocational rehabilitation is valid for nine months which means that the waiting period can be relatively long. There is also no guarantee that the planned rehabilitation measures will actually ever materialize. One of the interviewees (H6, rehabilitation expert) from an employee pension insurer called these cases "double clients" who often slip through the cracks if the distribution of responsibility between public employment offices and pension insurers fails to work. However, on the basis of the interviews, the need for cooperation between insurers and public employment offices is high because quite often there is a need to simultaneously utilize both public employment services and services provided by pension institutions. In these cases professionals should constantly be able to negotiate with each other concerning which services are suitable in each case and by which actor they should be organized. 
The interviewees brought up however that these negotiations have become more difficult than earlier due to recent reforms in 2013 after which the role of public employment offices in vocational rehabilitation has narrowed significantly. The reforms have been both conceptual and organizational. Firstly, the concept of vocational rehabilitation was completely removed from the legislation of public employment services. Furthermore, also the concept of impaired functional capacity is no longer included in the law. Secondly, from the organizational point of view, the most significant change was a massive reorganization in the distribution of work among professionals in public employment offices. According to several interviewees, the new distribution of work diminished the role of rehabilitation experts in the employment offices and thus weakened and muddled the know-how in RTW processes. At the same time also the staff of the employment offices decreased in relation to the number of clients.

These changes meant that public employment offices started to focus increasingly on unemployed people without any disabilities. This shift has caused confusion among professionals as regards the role of public employment offices in the ensemble of work disability services. Officially, public employment offices no longer provide vocational rehabilitation services whereas the Social Insurance Institution (Kela) and other insurance institutions hold the primary responsibility for them more clearly than before. In practice however, employment offices can still discretionarily provide some of the same services that were previously called vocational rehabilitation - though to a lesser degree and to a more select group of job-seekers than earlier - and this is still expected of them by other actors, as is clear from the interviews.

In sum, although there have also been problems in the cooperation of public employment offices and other actors before, according to the interviews the distribution of responsibility has become worse due to recent legislative and organizational reforms. What makes the situation complicated is that some actors, especially the professionals in pension institutions, have obviously not accepted the reduced role of public employment offices in vocational rehabilitation. 
With the employment administration (...) the cooperation has not been very good and especially the new reform has made the situation even worse. (H6, rehabilitation expert, employee pension institution)

\section{Networking Case Managers as the main Solution for better Cooperation}

The interviewees of the study had plenty of ideas on the development of cooperation. The proposed improvements can be classified into two intertwining themes. Firstly, a common view was that there should be more personal case managers who would have expertise predominantly on social and work-related issues related to RTW. It was hoped that in the best case scenario, case managers would have some kind of long-term overall responsibility for their clients, even though the service providers or payers were to change in the course of the process.

I don't know how it would ever work in practice, but someone should have total responsibility for this palette. There is a great deal of shifting of responsibility. (...) The problem is that the [RTW process] may stop at some point. And then there is not always somebody who could, in practice, tell the client how to proceed in the situation. That is for certain the biggest problem. (H1, work ability coach, occupational health care)

(...) there should be one professional from the beginning who would know the different services and unify them for a client to create a seamless package of services. (H11, rehabilitation expert, public employment office)

Secondly, on the basis of the interviews, an essential prerequisite for well-functioning case management is wide-ranging networking with colleagues in other organizations. 
Could we rethink our role so that the professional who catches the client would network really well and would know the affairs of the other actors reasonably well, and ensure (...) that the client isn't shunted back and forth between the organizations? (H9, insurance secretary/work ability advisor, Kela)

Many interviewees brought up the recent initiatives in Finland that have tried to implement different kinds of case managers in several organizations including the Social Insurance Institution (Kela), occupational health care, employers and public employment offices. However, the number of new case managers is low and many of the initiatives are still at a pilot phase. They have different names in different organizations, but importantly, they are all focused on the social and organizational side of work (dis)ability management and have a common goal based on individual support and professional networking. These new case management services resemble the vocational rehabilitation services that insurance institutions have, during the last decade, increasingly purchased from rehabilitation providers or provided themselves.

Nevertheless, according to the interviewees, there are several problems in the broader implementation of long-term comprehensive case management. Although most of the interviewees supported the new case management initiatives, they were unconvinced of their possibilities because of the scarce resources and the dispersed nature of the disability management system. Once again, the main concern was public employment services.

Following the path [of the client] is simply not possible in this model (...) with our low, tight resources. (H22, rehabilitation expert, public employment office)

But even if there was a sufficient number of personal case managers the main problem would possibly remain: how to coordinate the interaction of professionals working in different organizations within the dispersed system? As a way of reducing the inherent uncertainty of the 
complex field, some of the professionals brought up an idea of a single organization which would have an overall responsibility for individuals' RTW solutions.

It should then be (...) some kind of separate organization. Because now each of us is, anyway, kind of a prisoner of our own organization. (H10, insurance secretary/work ability advisor, Kela)

However, as establishing a single organization was considered unrealistic, the best solution, according to the professionals, is to enhance the cooperation and networking of existing organizations. On the basis of the interviews the distribution of responsibility between organizations could be more flexible, transitions between organizations should be faster and smoother, and there should be more case-specific discretion. The primary tool for achieving these goals was quite clear to the professionals: better communication.

First of all, many interviewees called for easier possibilities to contact professionals in other organizations, simply by increasing the availability of personal phone numbers and other contact details. Secondly, there is obviously a need for more comprehensive joint IT systems. It was desired that such systems could work between all the relevant actors. For example, a joint IT system could encompass at least employee pension institutions and other insurers, Kela and rehabilitation providers. According to several interviewees, it would be even more practical albeit quite unrealistic, if it also included public employment services and all health care providers.

Thirdly, without understating the significance of phone calls and IT systems for good communication, many of the interviewees demanded informal but well-planned meetings at which they could network and get acquainted with other professionals. They were quite unanimous in that the actors should be better acquainted with both each other personally and the services of other organizations. 
I believe in face-to-face communication. If we create good relations, the cooperation will work. (H7, social worker, special health care)

This work can't be done alone. (H22, rehabilitation expert, public employment office)

There could be annual regional meetings for example with rehabilitation providers, employment administration and Kela (H3, career coach, rehabilitation provider)

Finally, as an essential obstacle to smooth cooperation the interviewees criticized the insufficient know-how of the personnel in health care, especially physicians in primary and special health care, when it comes to work ability issues, for example when drawing up rehabilitation plans. Accordingly, some interviewees suggested additional education on RTW issues for physicians. From a more general point of view a common wish in the interviews was that the role of nonmedical professions and case managers should be increased in RTW interventions. In relation to this, many welcomed the ongoing interdisciplinary development where expertise in social and work-related issues is gradually gaining a stronger foothold in the management of work disabilities.

\section{Discussion}

The study identified two main sources of uncertainty in the cooperation of RTW professionals: problems in the communication and distribution of responsibility. Although these problems can be analysed separately, in reality they are deeply intertwined. Problems in both of these areas seem to stem largely from organizational rigidity and the inability to put into practice flexible solutions in the cooperation between different organizations. However, communication is somehow the more fundamental of these two themes as problems in communication -whether related to case-specific negotiations between professionals or more structural issues like IT systems - appear to often be one of the main reasons if the distribution of work does not work optimally. At the least, 
communication can be an important way in overcoming the organizational rigidities behind the problems in the distribution of responsibility.

These findings are in line with many earlier studies which have stressed quite similar issues as the most significant barriers to interorganizational cooperation in the arena of work disability management $[2,5,6,20]$. However, our study distinguished notable regional differences depending primarily on the scale of the local network - in how smoothly the cooperation works. We have also emphasized the specific role of the employment administration system in the RTW processes and in the problems linked to cooperation. Furthermore, the study brought up some key ideas that the interviewees presented for improving the cooperation. In the remaining sections, the results are discussed in relation to two important areas of improvement that emerged in the analysis. These are, firstly, the possibilities of systematic networking including all the relevant stakeholders, and secondly, the requirement for the expansion of expertise in the management of work disabilities.

\section{The Possibilities of systematic Networking}

One of the biggest concerns regarding the RTW processes in Finland is that nobody has a clear comprehensive responsibility for the clients [17, 32]. This view was also present in the interviews. However, as the professionals were sceptical about the possibilities of a single organization in taking the responsibility of the whole path of a client, better cooperation and networking by the existing organizations and professionals seems to be the only choice. A common suggestion was that there should be more personal case managers and systematic networking between them and between the organizations they work for. On the basis of the interviews, important elements in making the cooperation smoother include, firstly, quick and easy ways to contact other professionals, secondly, comprehensive joint ITsystems between different organizations, and 
thirdly, regular possibilities for face-to-face meetings. An important finding in the study was that the cooperation works better on a smaller scale as the first and the last of these three elements are easier to put into practice in smaller localities. Hence, an essential question is, would the cooperation be easier also in bigger cities if the management of RTW processes was decentralized to smaller networks or teams with more possibilities for informal ways of communication.

All in all, the study shows how the management of RTW processes requires intensive integration of all the relevant actors. Based on the interviews with the professionals, the study argues for the significance of close cooperation of different stakeholders in decreasing the uncertainty in a complex system of numerous actors. And as the stakeholders often have different interests, values and language [30], systematic networking and regular negotiations where professionals can become acquainted with each other seem to be an indispensable prerequisite for the functioning cooperation.

The problems in the communication and distribution of responsibility described in this article are, to some extent, relevant to various client groups but in particular for unemployed people with work disabilities. This is due to the problems in the cooperation between public employment offices and other organizations. Interestingly, this situation has some similar elements with the difficulties in the cooperation between public employment offices and other RTW stakeholders in Sweden [8, 24]. In this article we argue that, in studying and developing the cooperation and networking in the multi-actor management of work disabilities, the employment administration system should be taken seriously into account in addition to the workplace, insurance and health care systems. Both the interviews and the literature affirms that the importance of employment services in the ensemble of RTW is related to the fact that shorter or longer periods of unemployment are fairly common among people with disabilities $[24,25,26]$. In many earlier empirical studies and also in work disability management models the role of public employment services as an important stakeholder has not been sufficiently recognized. In this study the crucial role of employment administration in 
the network came up through the observation made by the interviewees that the recent changes and reduction in work disability services in public employment offices in Finland has made the cooperation, in many cases, worse than before. Also some managers of employment administration appear ready to admit that public employment offices are no longer able to adequately serve those who are in the most difficult situations, that is, particularly unemployed persons with disabilities $[33]$.

Accordingly, the article claims that, in Finland, the problems in the cooperation of employment offices and other actors have resulted in an unequal situation between employees and unemployed persons with work disabilities. The availability of RTW interventions is much worse for the unemployed compared to employees. Similar inequalities have also been found in other countries, for example in Sweden [24, 34].

\section{The Expansion of Expertise and the dynamic Relativity of Work Disability}

The interviews of this study gave empirical evidence for the idea that work (dis)ability is a very complicated phenomenon that is managed and moulded in complex, case-specific and dynamic relations between different professions, organizations and clients. This is the rationale why the interviewees stressed the importance of the expansion of (nonmedical) expertise in the field, partly through education and partly by increasing the role of other professionals than physicians. As regards the case of Finland, there are some new signs of a gradual movement towards this direction. This movement materializes, for example, in the efforts and aspirations to increase the role of personal RTW coordinators and other kinds of case managers in occupational health care, workplaces, insurance institutions and public employment services.

The ideas of the professionals regarding the expansion of expertise support the evolving perspective according to which work (dis)ability is a relative and dynamic concept depending on various 
individual, organizational and societal dimensions [35]. This means that work disability can be understood as a changing relationship between a person with a "health condition" and the “environment" $[2,10,36,37]$. In this article the environment consists of various professional stakeholders around the person with disabilities including the workplace, health care, insurance and employment administration. As a whole the multidimensionality of work (dis)ability is also composed of many informal "environmental" components, such as family, home life and various kinds of resources $[38,39,40]$. This multidimensionality and the dynamic relativity of disability emphasize the importance of an interdisciplinary and interorganizational approach to the prevention, evaluation and management of work disability.

\section{Strengths and Limitations}

The data collection of the study was designed so that all the relevant stakeholders would be represented. This goal was achieved with the exception that we did not have any interviewees from primary health care, which can be considered a minor limitation for the study. However, the most important health care actors in work disability management - occupational and special health care were included in the study. The number of the interviewees (24) can be considered relatively high in this kind of qualitative research framework including lengthy and in-depth individual interviews. As the interviewees were from two different regions, some interesting comparison between the metropolitan area and smaller localities was possible, though the inclusion of more than two regions could have yielded more diverse and systematic information on local differences.

Thematic semi-structured interviews are an indispensable form of research material. This kind of data can bring out such grass-roots level experiences of mundane practices that cannot be studied using other kinds of data. Hence, an essential strength of the study is the possibility to highlight the ostensibly subjective views of the interviewees that may otherwise stay hidden even though they 
may be widely shared among professionals. There is, nevertheless, the possibility that some of the personal views of the interviewees may receive too much attention. To avoid this, the validity and relevance of the viewpoints of the informants were evaluated by assessing how widely and unanimously the experiences were shared among the interviewees - though exact quantification of the answers was not sensible because of the heterogeneity of the interviews and the interviewees. In other words, as the interviews were not strictly structured and the interviewees represented several different organizations and various professions, the interviews are not systematically comparable and it would have been misleading to simply quantify the answers. We have mentioned however, if an opinion or idea was raised by several or only a few or one of the interviewees. At the same time, it is noteworthy that in this kind of qualitative study even a single statement from one of the informants can be valuable if it illuminates a more general phenomenon. Another way to critically evaluate the interviewees' interpretations was to analyse them in relation to existing literature on the topic. Moreover, the results have also been validated through feedback in several scientific congresses and also by discussing the results with various work disability professionals after the initial interviews.

\section{Conclusions}

The study shows how RTW interventions, implemented in a complex network of numerous stakeholders, require intensive integration and cooperation of the relevant actors. The article argues for the importance of systematic networking and stresses especially the role of public employment services in the multi-actor management of work disabilities. The article contributes to existing work disability case management models by suggesting the employment administration system as an important component in addition to health care, workplace and insurance systems. The study also highlights the need for expansion of expertise in the field. 


\section{Acknowledgements}

We would like to thank all the professionals who agreed to be interviewed. We would also like to thank Raija Gould, Susan Kuivalainen and Jukka Kivekäs for their comments on earlier versions of the paper. Finally, we gratefully acknowledge the helpful suggestions of the two anonymous reviewers.

\section{Declaration of Interest}

The authors report no conflicts of interest.

\section{Ethical Standards}

All procedures performed in the study involving human participants were in accordance with the ethical standards of the national research committee and with the 1964 Helsinki declaration and its later amendments or comparable ethical standards.

\section{References}

1. Brunarski D, Shaw L, Doupe L. Moving toward virtual interdisciplinary teams and a multi-stakeholder approach in community-based return-to-work care. Work. 2008;30:329-36.

2. $\quad$ Franche RL, Baril R, Shaw W, Nicholas M, Loisel P. Workplace-based return-to-work interventions: optimizing the role of stakeholders in implementation and research. J Occup Rehabil. 2005;15:525-42.

3. Friesen MN, Yassi A, Cooper J. Return-to-work: The importance of human interactions and organizational structures. Work. 2001;17:11-22.

4. Holwerda A, Fokkens AS, Engbers C, Brouwer S. Collaboration between mental health and employment services to support employment of individuals with mental disorders. Disabil Rehabil. 2015;37:1-7.

5. Nilsing E, Soderberg E, Bertero C, Oberg B. Primary healthcare professionals' experiences of the sick leave process: a focus group study in Sweden. J Occup Rehabil. 2013;23:450-61. 
6.

Pransky G, Shaw W, Franche RL, Clarke A. Disability prevention and communication among workers, physicians, employers, and insurers--current models and opportunities for improvement. Disabil Rehabil. 2004;26:625-34.

7. Ståhl C, Svensson T, Petersson G, Ekberg K. The work ability divide: holistic and reductionistic approaches in Swedish interdisciplinary rehabilitation teams. J Occup Rehabil. 2009;19:264-73.

8. $\quad$ Ståhl C, Svensson T, Petersson G, Ekberg K. A matter of trust? A study of coordination of Swedish stakeholders in return-to-work. J Occup Rehabil. 2010;20:299-310.

9. Loisel P, Durand M-J, Berthelette D, Vézina N, Baril R, Gagnon D, Larivière C, Tremblay C. Disability Prevention. Dis-Manage-Health-Outcomes. 2001;9:351-60.

10. Pransky GS, Loisel P, Anema JR. Work disability prevention research: current and future prospects. J Occup Rehabil. 2011;21:287-92.

11. Anema JR. Low back pain, workplace intervention and return-to-work. Amsterdam: Vrije University; 2004.

12. Lincoln AE, Feuerstein M, Shaw WS, Miller VI. Impact of Case Manager Training on Worksite Accommodations in Workers' Compensation Claimants With Upper Extremity Disorders. Journal of Occupational and Environmental Medicine. 2002;44:237-45.

13. Nevala N, Pehkonen I, Koskela I, Ruusuvuori J, Anttila H. Workplace accommodation among persons with disabilities: a systematic review of its effectiveness and barriers or facilitators. J Occup Rehabil. 2015;25:432-48.

14. Shaw W, Hong QN, Pransky G, Loisel P. A literature review describing the role of return-to-work coordinators in trial programs and interventions designed to prevent workplace disability. J Occup Rehabil. 2008;18:2-15.

15. Miettinen S, Ashorn U, Lehto J. Talking about the institutional complexity of the integrated rehabilitation system - the importance of coordination. Int J Integr Care. 2013;13:e007.

16. Pulkki JM, Rissanen P, Raitanen JA, Viitanen EA. Overlaps and accumulation in the use of rehabilitation services. International Journal of Rehabilitation Research. 2011;34:255-60.

17. OECD. Sickness, Disability and Work: Breaking the Barriers. Vol. 3: Denmark, Finland, Ireland and the Netherlands. Paris2008.

18. OECD. Sickness, Disability and Work. Breaking the Barriers. A Synthesis of Findings across OECD Countries. Paris2010.

19. Schmollinger MG. Disability policy, rehabilitation and participation in Germany.

Kuntoutus. 2008;31:29-35.

20. Wihlman U, Lundborg CS, Axelsson R, Holmstrom I. Barriers of inter-organisational integration in vocational rehabilitation. Int J Integr Care. 2008;8:e52.

21. Loisel P. Intervention for return to work--what is really effective? Scand J Work Environ Health. 2005;31:245-7.

22. Pomaki G, Franche RL, Murray E, Khushrushahi N, Lampinen TM. Workplace-based work disability prevention interventions for workers with common mental health conditions: a review of the literature. J Occup Rehabil. 2012;22:182-95.

23. Wåhlin C, Ekberg K, Persson J, Bernfort L, Öberg B. Association Between Clinical and Work-related Interventions and Return-to-Work for Patients with Musculoskeletal or Mental Disorders. Journal of Rehabilitation Medicine. 2012;44:355-62.

24. Eriksson UB, Engstrom LG, Starrin B, Janson S. Falling between two stools; how a weak co-operation between the social security and the unemployment agencies obstructs rehabilitation of unemployed sick-listed persons. Disabil Rehabil. 2008;30:569-76.

25. Gould R, Laaksonen M, Kivekäs J, Ropponen T, Kettunen S, Hannu T, Käppi I, Ripatti P, Rokkanen T, Turtiainen S. Työkyvyttömyyseläkettä edeltävät vaiheet. Asiakirjaaineistoon perustuva tutkimus. [Phases preceding disability pension. A study based on documentary data]. Helsinki: Finnish Centre for Pensions; 2014. 
26.

Laaksonen M, Blomgren J, Gould R. Työkyvyttömyyseläkkeelle siirtyneiden sairauspäiväraha-, kuntoutus- ja työttömyyshistoria. Rekisteripohjainen tarkastelu. [Sickness allowance, rehabilitation and unemployment history of disability retirees. A register based study]. Helsinki: Finnish Centre for Pensions; 2014.

27. Lerner D, Adler DA, Chang H, Lapitsky L, Hood MY, Perissinotto C, Reed J, McLaughlin TJ, Berndt ER, Rogers WH. Unemployment, Job Retention, and Productivity Loss Among Employees With Depression. Psychiatric Services. 2004;55:1371-8.

28. Ericson RV, Doyle A. Uncertain business. Risk, Insurance, and the Limits of Knowledge. Toronto: University of Toronto Presss; 2004.

29. O'Malley P. Risk, Uncertainty and Government. London: GlassHouse Press; 2004. 30. Loisel P, Buchbinder R, Hazard R, Keller R, Scheel I, van Tulder M, Webster B. Prevention of work disability due to musculoskeletal disorders: the challenge of implementing evidence. J Occup Rehabil. 2005;15:507-24.

31. Costa-Black KM, Feuerstein M, Loisel P. Work Disability Models: Past and Present. In: Loisel P, Anema JR, editors. Handbook of Work Disability Prevention and Management. New York: Springer; 2014. p. 71-93.

32. Lehto M. Kaikki mukaan! Osatyökykyiset työmarkkinoilla. [Including all! Partially disabled in the labour market]. Helsinki: Ministry of Social Affairs and Health; 2011.

33. Eronen A, Hakkarainen T, Londén P, Peltosalmi J. Sosiaalibarometri 2014. Ajankohtainen arvio hyvinvoinnista, palveluista sekä palvelujärjestelmän muutoksesta. [Social barometer 2014. Topical evaluation of welfare, services and the changes in the service system]. Helsinki: SOSTE Suomen sosiaali ja terveys ry; 2014.

34. Burstrom B, Nylen L, Clayton S, Whitehead M. How equitable is vocational rehabilitation in Sweden? A review of evidence on the implementation of a national policy framework. Disabil Rehabil. 2011;33:453-66.

35. Lederer V, Loisel P, Rivard M, Champagne F. Exploring the diversity of conceptualizations of work (dis)ability: a scoping review of published definitions. J Occup Rehabil. 2014;24:242-67.

36. Angeloni S. Integrated Disability Management. An Interdisciplinary and Holistic Approach. Sage Open. 2013:1-15. Epub 28 October.

37. Stone DA. The Disabled State. Philadelphia: Temple University Press; 1984.

38. Gould R, Ilmarinen J, Järvisalo J, Koskinen S, editors. Dimensions of Work Ability. Results of the Health 2000 Survey. Helsinki: Finnish Centre of Pensions, The Social Insurance Institution, National Public Health Institute, Finnish Institute of Occupational Health; 2008. 39. Ilmarinen J. Work ability - a comprehensive concept for occupational health research and prevention. Scandinavian Journal of Work, Environment \& Health. 2009;35:1-5.

40. Ilmarinen J, Gould R, Järvikoski A, Järvisalo J. Diversity of Work Ability. In: Gould R, Ilmarinen J, Järvisalo J, Koskinen S, editors. Dimensions of Work Ability Results of the Health 2000 Survey. Helsinki: Finnish Centre of Pensions, The Social Insurance Institution, National Public Health Institute, Finnish Institute of Occupational Health; 2008. p. 13-24. 
Table 1. Titles, organizations and region of the interviewees.

\begin{tabular}{|c|c|c|c|}
\hline & Title & Organization & Region \\
\hline $\mathrm{H} 1$ & work ability coach & occupational health care & 1 \\
\hline $\mathrm{H} 2$ & rehabilitation manager & rehabilitation provider & 1 \\
\hline H3 & career coach & rehabilitation provider & 1 \\
\hline $\mathrm{H} 4$ & pension expert & employee pension insurer & 1 \\
\hline H5 & rehabilitation expert & employee pension insurer & 1 \\
\hline H6 & $\begin{array}{l}\text { rehabilitation expert and pension } \\
\text { expert (two interviewees) }\end{array}$ & employee pension insurer & 1 \\
\hline $\mathrm{H} 7$ & social worker & special health care & 1 \\
\hline H8 & social worker & special health care & 1 \\
\hline H9 & $\begin{array}{l}\text { insurance secretary/work ability } \\
\text { advisor }\end{array}$ & Kela and labour force service centre & 1 \\
\hline H10 & $\begin{array}{l}\text { insurance secretary/work ability } \\
\text { advisor }\end{array}$ & Kela and labour force service centre & 1 \\
\hline H11 & rehabilitation expert & public employment office & 1 \\
\hline H12 & psychologist & public employment office & 1 \\
\hline H13 & occupational physician & occupational health care & 2 \\
\hline H14 & personnel coordinator & $\begin{array}{l}\text { special health care (personnel } \\
\text { administration) }\end{array}$ & 2 \\
\hline H15 & personnel manager & $\begin{array}{l}\text { private company (personnel } \\
\text { administration) }\end{array}$ & 2 \\
\hline H16 & project manager & rehabilitation provider & 2 \\
\hline H17 & rehabilitation manager & rehabilitation provider & 2 \\
\hline H18 & rehabilitation assessor & rehabilitation provider & 2 \\
\hline H19 & rehabilitation planner & special health care & 2 \\
\hline $\mathrm{H} 20$ & rehabilitation advisor & Kela and labour force service centre & 2 \\
\hline $\mathrm{H} 21$ & benefits officer/ work ability advisor & Kela & 2 \\
\hline $\mathrm{H} 22$ & rehabilitation expert & public employment office & 2 \\
\hline $\mathrm{H} 23$ & service instructor & labour force service centre & 2 \\
\hline
\end{tabular}

